\title{
Behavioural interactions between the lizard Takydromus tachydromoides and the praying mantis Tenodera aridifolia suggest reciprocal predation between them
}

\author{
Miyuki Fukudome ${ }^{1} \cdot$ Yoshifumi Yamawaki $^{1}$
}

Received: 9 September 2015/Accepted: 1 April 2016/Published online: 18 April 2016

(C) Japan Ethological Society and Springer Japan 2016

\begin{abstract}
The Japanese lacertid lizard Takydromus tachydromoides and the praying mantis Tenodera aridifolia are sympatric generalist predators feeding on similar prey. To confirm reciprocal predation between them, we observed the behavioural interactions between the lizards and the mantises of different sizes in a laboratory condition. The lizards caught small mantises (from first to fifth instars), but sometimes escaped from large mantises (from sixth instar to adult). Large mantises occasionally showed catch responses to the lizards. The lizards sometimes caught the mantis without a tongue-flick response (sampling of chemical cues), and they sometimes did not catch the small mantises showing immobile or cryptic responses that prevent visual detection. These results suggested the primary role of vision on recognition of the mantis as a prey. The lizards spent a longer time to approach larger mantises. The time from orienting to catch was longer when the lizards showed tongue-flick responses. The lizard also spent a longer time before deciding to escape from the mantis than to catch it. Biological significance of these differences in timing was discussed.
\end{abstract}

Keywords Predator-prey interaction - Prey recognition . Escape - Intraguild predation - Anti-predator behaviour . Lizard · Mantis

Electronic supplementary material The online version of this article (doi:10.1007/s10164-016-0468-6) contains supplementary material, which is available to authorized users.

Yoshifumi Yamawaki

y.yamawaki@kyudai.jp

1 Department of Biology, Faculty of Science, Kyushu University, Fukuoka 819-0395, Japan

\section{Introduction}

Elucidating the interactions between predators and prey is essential to understand the foraging and escape strategies. A predator-prey relationship is not always stable and can be reversed by ontogenetic changes in body size (Woodward and Hildrew 2002). The ground skinks, for example, prey upon small spiders (e.g. Brooks 1963), but adult wolf spiders can prey upon juvenile skinks (Rubbo et al. 2001). Although several studies have focused on this reciprocal predation (e.g. Rubbo et al. 2001, 2003), little attention has been paid to its impact on foraging and escape strategies. Animals under reciprocal predation need to assess potential prey and catch only proper prey for avoiding a predatory attack by the prey, and they might have relatively complex strategies for foraging and escape.

The interactions between lizards and praying mantises can be a good model for investigating the effects of reciprocal predation (and ontogenetic reversals) on foraging and escape strategies. The Japanese lacertid lizard Takydromus tachydromoides is an opportunistic generalist predator, its diet consisting chiefly of insects and spiders, and occasionally other small arthropods and gastropods (Jackson and Telford 1975). After visual detection of prey, the lizard approaches, snaps, kills and eats it (Johki and Hidaka 1979). This predatory sequence is sometimes accompanied with tongue-flick behaviour (Johki and Hidaka 1979, 1982), which is active sampling of chemical cues (e.g. Burghardt 1973; Cooper 1990a, b). It has been suggested that birds and snakes prey upon Ta. tachydromoides (Telford 1997). The lizard shows several kinds of anti-predator responses such as escape run (fleeing), immobility and tail waving (Mori 1990, 1991). The tail waving is thought to draw a predatory attack towards the tail so that the lizard can employ tail autotomy for survival 
(e.g. Mori 1990; Rubbo et al. 2001; Telemeco et al. 2011). Takydromus tachydromoides is observed on various weedy zones such as grassland of paddy margin and wooded hillside (Jackson and Telford 1975; Telford 1997). A small mantis is one of diets of Ta. tachydromoides in the field (Jackson and Telford 1975), suggesting that the mantis and the lizard are sympatric.

The praying mantis Tenodera aridifolia is also an opportunistic generalist predator capturing many kinds of insect species (Barrows 1984). The mantises detect prey mainly by vision and capture it with their raptorial forelegs. Against their predators, such as birds and lizards, the mantises show various defensive responses depending on their developmental stage (e.g. Liske et al. 1999; Watanabe and Yano 2010). Small mantises tend to show immobility and cryptic responses for avoiding detection by predators, while large mantises tend to show deimatic (Maldonado 1970) and defensive strike responses for threating predators. It has been suggested that a large mantis occasionally preys upon a small lizard (Kevan 1985; Jackson and Telford 1975). However, little is known about the effects of ontogenetic changes in body size on the interactions between the lizard and the mantis (but see Hasegawa and Taniguchi 1996).

In the present study, we observed the interactions between Ta. tachydromoides and Te. aridifolia of different sizes in a laboratory condition. We addressed following three issues, focusing on the lizard responses. First, to confirm reciprocal predation between them (and ontogenetic reversals), we examined the effects of mantis size on the responses of the lizard. If the lizard catches small mantises but escapes from large mantises, this suggests reciprocal predation between them. We also examined the effects of mantis defence on lizard responses. Second, we analysed behavioural responses of the lizard in order to understand the sensory cues that the lizard uses to detect and identify prey. If catching prey is not frequently preceded with tongue-flick, for example, it suggests a primary role of vision in prey recognition. Finally, to investigate the foraging and escape strategies in the lizard, we measured the time interval between lizard responses such as the time from prey detection to catch. The time required for the decision to catch or to escape provides clues for understanding the decision-making processes in the lizards.

\section{Materials and methods}

\section{Animals}

A total of 12 adult Ta. tachydromoides and hundreds of Te. aridifolia were used without distinction of sex. The lizards were collected in April, May and June 2011 at the
Hakozaki campus of Kyushu University in Fukuoka, Japan. Snout-vent length (SVL) of the lizards was ranged from 50 to $60 \mathrm{~mm}$. They were kept in plastic cages $(40 \times 25 \mathrm{~cm}$ and $25 \mathrm{~cm}$ height) individually or in pairs under a $12 \mathrm{~h}: 12 \mathrm{~h}$ light/dark cycle at $25 \pm 3{ }^{\circ} \mathrm{C}$. They were given access to water ad libitum and fed with European house crickets (Acheta domesticus) three times a week. A UV lamp $(13 \mathrm{~W})$ illuminated the cages to maintain healthy conditions for the lizards (e.g. for basking). After all the experiments were finished, the lizards were released at the original capture site.

The mantises were reared from eggs collected in the suburbs of Fukuoka. The nymphs and adults of the mantises were fed with fruitflies (Drosophila melanogaster) or nymphs of house crickets three times a week. In order to avoid cannibalism, nymphs older than the third instar were kept individually. The length (from head to the last segment of the abdomen) of the mantises ranged from 12 to $76 \mathrm{~mm}$ (Table 1).

\section{Experimental procedures}

We used the lizards and the mantises that were not fed at the day of experiments. During experiments, the lizard was kept in a glass cage $(18 \times 45 \mathrm{~cm}$ and $20 \mathrm{~cm}$ height $)$ with a white floor (Fig. 1). The inside of the cage wall was covered with liquid paraffin to prevent mantises from climbing the wall. Behavioural responses of the lizard and the mantis were recorded from a dorsal view with a video camera (Sony, DCR-TR V950) at a speed of 30 frames/s under fluorescent lamp illumination. Experiments were conducted between 10:00 and 18:00 at $27 \pm 3{ }^{\circ} \mathrm{C}$.

The lizards were presented with mantises of different sizes in an ascending order: each lizard received three trials with first to third instar mantises and two trials with fourth instar to adult mantises. The interval between trials was basically more than 1 day, but several trials were occasionally conducted for the same lizard on the same day when the lizard readily ate the mantis. At the start of

Table 1 The length of the mantis

\begin{tabular}{ll}
\hline Mantis instar & Mean \pm SD $(\mathrm{mm})$ \\
\hline 1 & $11.6 \pm 1.6$ \\
2 & $15.7 \pm 1.4$ \\
3 & $20.6 \pm 1.9$ \\
4 & $30.7 \pm 1.6$ \\
5 & $42.5 \pm 6.3$ \\
6 & $57.9 \pm 6.2$ \\
7 & $69.7 \pm 1.6$ \\
Adult & $76.4 \pm 5.3$ \\
\hline
\end{tabular}


a
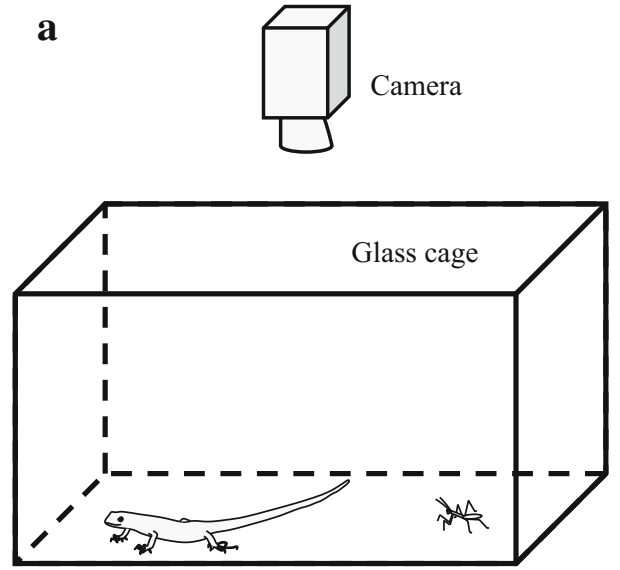

b

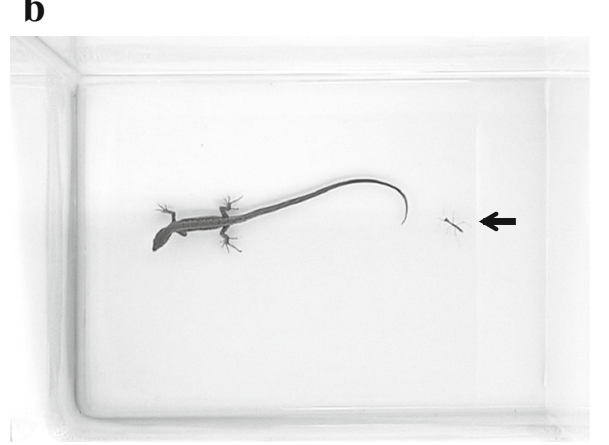

Fig. 1 Experimental set-up. a Schematic drawing of the set-up. During experiments, the lizard Takydromus tachydromoides and the mantis Tenodera aridifolia were kept in a glass cage $(18 \times 45 \mathrm{~cm}$ and $20 \mathrm{~cm}$ height). Their behavioural responses were recorded from a dorsal view with a video camera. b A sample frame in a video recording of the lizard and the mantis (arrow). Brightness and contrast were adjusted

a trial, a lizard was gently introduced into the glass cage. Then, a mantis was dropped into the cage at a position behind the lizard to avoid any disturbance by the experimenter. Their behaviours were observed until the lizard ate the mantis or ran away from it. When the lizard showed neither behaviour within $30 \mathrm{~min}$, that trial was discarded and a new trial was re-attempted on another day. When the mantis tried to catch the lizard, we immediately stopped the trial and removed the mantis. Hence, no lizard was injured by a mantis. When the lizard did not eat the mantis, we subsequently offered it a cricket to ascertain whether the lizard was hungry (Hasegawa and Taniguchi 1996). If the lizard also did not eat the cricket, data in that trial were discarded and a new trial was re-attempted on another day. Hence, we used data from trials in which the lizard ate a prey (a mantis or a cricket). Although the hunger level of the lizard was not strictly controlled, the motivation for predation was considered to exceed a certain level during the experiments (Hasegawa and Taniguchi 1996).

\section{Classification of behavioural responses}

Escape was defined as turning and running away from the mantis. According to Johki and Hidaka (1979), predatory responses of Ta. tachydromoides consist of seven successive steps: 'watch', 'approach', 'smell' by tongue, 'touch' by tongue, 'snap', 'kill', and 'eat' the prey. In the present study, however, predatory steps were defined as follows. Orienting: turning the head quickly towards the prey; approach: walking towards the prey; tongue-flick: emitting its tongue; and catch: biting the prey. Because it was difficult to detect touching the prey with the tongue, we did not discriminate between the 'smell' and 'touch' defined by Johki and Hidaka (1979) and referred to both as tongueflick. The orienting and approach responses suggest the detection of visual cues of the prey, whereas tongue-flick responses suggest the investigation of chemical cues (e.g. Cooper 1990a). We did not observe predatory steps after 'snap'.

The mantis responses to the lizard were classified into seven, as follows. Immobility: staying without any movements; cryptic reaction: lowering the prothorax, stretching the prothoracic legs, and stretching the abdomen backward; subcryptic reaction: lowering the prothorax slightly and retracting the forelegs under the prothorax (Watanabe and Yano 2010); escape run: running away from the lizard; deimatic reaction: raising the prothorax and extending the forelegs laterally (Maldonado 1970); defensive strike: attacking the lizard by the forelegs during a deimatic reaction; and catch: approaching and lunging towards the lizard with capturing movements of the forelegs. When any of the above responses was not observed, we defined it as no-response. In some trials, several responses were observed sequentially. For example, some mantises showed a cryptic reaction first, and then showed escape run after the lizard touched it. All mantis responses in a trial were recorded.

\section{Behavioural analysis}

Video recordings of lizard and mantis responses were digitised with Adobe Premiere Elements 3.0 (Adobe Systems) and used for analysis. For the analysis of behavioural occurrence, we recorded the occurrence of each response of the lizard during the first encounter period with the mantis in each trial, although several encounters were observed in some trials. The encounter period started when either the lizard or the mantis detected the other and ended when either of them showed catch or escape run. Thus, no occurrence of the lizard responses was recorded when the mantis detected the lizard and ran away before the lizard detected the mantis. The response rates were calculated for each lizard by dividing the numbers of trials in which the 
response occurred by the total numbers of trials. In addition, we counted the numbers of catch and escape responses accompanied with and without tongue-flick to examine the importance of chemical cues for deciding whether to catch or escape.

It is possible that the mantis defensive responses affect the lizard responses. To examine the effects of the mantis defence on the lizard catch responses, the data of the mantis responses in the first encounter were divided into two groups according to whether or not the lizard caught the mantis. As immobility, cryptic and subcryptic responses have a primary defensive function that prevents predation at detection and identification stages (Robinson 1969), we pooled these data for each mantis instar. We also pooled data of deimatic and defensive strike responses because of their secondary defensive function which prevents the later stage of predation (Robinson 1969). We also examined the effects of mantis primary defence on the tongue-flick responses of the lizard. It is possible that the lizard tries to detect chemical cues when visual cues are insufficient, i.e. the prey shows little movement. To test this, the pooled data of young mantises (from first to third instars) were divided according to whether or not the mantis showed primary defences.

We measured the time between responses (for example, the time from orienting to catch), because it likely reflects the time required for decision making by the lizard. For the analysis of behavioural timings, responses of the lizard during all encounter periods in each trial were used to increase the sample size. The time interval between the onsets of two different responses (for example, time from orienting to catch) was measured by counting the number of video frames between these onsets. The definition of the onset of the each response was as follows. Orienting: the frame prior to the first frame where the turning movement of head was observed; approach: the frame prior to the first frame where the displacement of the body towards the prey was observed; catch: the first frame where the jaws touched the prey; and tongue-flick: the first frame where the emitted tongue was observed after orienting or approach. When the lizard turned and ran away from the mantis, we also measured the time from orienting to escape. The definition of the onset of the escape run was the frame prior to the first frame where the head started turning away. We measured the timing of the first tongue-flick response after orienting or approach to examine the effects of supplementing chemical cues on the decision-making process after visual detection of the prey.

If the deimatic responses of the mantis lower the motivation of a lizard for catching the mantis, the time from orienting to catch would be longer in trials in which the mantis showed a deimatic response than a trial without it. To test this possibility, data of middle mantises (fourth and fifth instars) were divided into two groups according to whether or not the mantis showed a deimatic response.

\section{Statistics}

SigmaPlot 12 for Windows (Systat Software) was used for all statistical analyses. The occurrence data of lizard behaviours were analysed using repeated-measures binary logistic regression, and the Wald statistic was used to determine whether a tested independent variable (the mantis instar) was a significant predictor of occurrence. The categorical independent variable (the lizards) was converted into an equivalent set of dummy variables using reference coding.

For the other analyses, lizard responses were treated as if they were each performed by a separate animal (independent) because there were many missing observations for some lizards. In response data to each mantis instar, three responses of the same lizard were treated as independent at maximum. When response data to all mantis instars were pooled, the maximum number of responses treated as independent was 18. Analysis of correlation was carried out with Spearman rank-order correlation, and its correlation efficient is denoted by $r_{s}$. The Mann-Whitney $U$ test (MWT), Fisher's exact test, and Chi-square test were also used.

\section{Ethical note}

All experiments were performed under the guidance of Animal Experiments in Faculty of Sciences, Kyushu University, and the law (number 105) of Japanese government. We used the minimum number of lizards necessary to achieve the research objectives. Experimental procedures did not cause any unnatural pain to the lizard.

\section{Results}

Responses of nine lizards to mantises of each instar were used for analysis of behavioural occurrence because the other three lizards died before completing the experiments. For analysis of behavioural timing, however, a total of 305 responses of 12 lizards were used. To examine the effects of mantis instar on mantis defensive responses, a total of 305 mantis responses evoked by 12 lizards were used.

\section{Effects of the mantis instar on occurrence of lizard responses}

The lizards caught small mantises (from first to fifth instars), but sometimes escaped from large mantises (from 
sixth instar to adult). The effects of the mantis instar on occurrence probabilities of catch and escape were significant (Fig. 2a; binary logistic regression, $n=171$; catch: Wald $\chi^{2}=46.751, P<0.001$; escape: Wald $\chi^{2}=20.717$, $P<0.001)$. As the mantis instar increased, the lizard caught the mantis less frequently and escaped from it more frequently. During typical catching of small mantises, the lizard approached the mantis straightforwardly and bit it (Supplemental Movie S1). Occasionally, there was a brief pause before biting. In response to large mantises, the lizard rarely approached them. When the large mantis approached the lizard, the lizard occasionally waved its tail (S2) before running away from the mantis. This tail waving seemed to elicit visual orienting by the mantis towards the tail.

Orienting and approach responses of the lizard preceded the most catch responses, but tongue-flick responses did not always precede either catch or escape responses. The lizard showed orienting, approach and tongue-flick responses less frequently as the mantis instar increased (Fig. 2b; $n=171$; orienting: Wald $\chi^{2}=31.032$, $P<0.001$; approach: Wald $\chi^{2}=24.238, P<0.001$; tongue-flick: Wald $\left.\chi^{2}=10.885, P<0.001\right)$. The mean response rate of orienting and approach to the first instar mantis was smaller than that of catch because the small mantises sometimes approached the lizard and they were caught before the lizard showed orienting or approach. The catch and escape responses were not always accompanied by tongue-flick (Fig. 2c, d).

\section{Effects of mantis instar on behavioural timing in lizards}

There was no significant correlation between the mantis instar and each behavioural time (Fig. 3; from orienting to catch: $n=112, r_{\mathrm{s}}=0.0267, P=0.779$; from approach to catch: $n=75, r_{\mathrm{s}}=0.136, P=0.243$; from tongue-flick to catch, $\left.n=47, r_{\mathrm{s}}=0.114, P=0.445\right)$. However, when data were pooled and divided into two groups, i.e. responses to small (first to third instars) and large (fourth instars to adults) mantises, time from approach to catch against large mantises were significantly longer than against small mantises (MWT, $n_{1}=16, n_{2}=59$, $U=267.0, P=0.008)$. The medians of those times were 5.6 and $3.4 \mathrm{~s}$, respectively. There was no significant difference in time from orienting or tongue-flick to catch between responses to large and small mantises (MWT; from orienting to catch: $n_{1}=29, n_{2}=83, U=1134.5$, $P=0.649$; from tongue-flick to catch, $n_{1}=15, n_{2}=32$, $U=199.0, P=0.355)$. The median times from orienting
Fig. 2 Effects of the mantis instar on lizard responses. a Mean response rate and standard error (SE) of catch and escape in lizards as a function of the mantis instar. Data were from 19 presentations to each of 9 lizards $(n=171)$. b Mean response rate and SE of orienting, approach and tongueflick. $\mathbf{c}$ The number of catches accompanied with tongue-flick $(n=34)$ and without it $(n=52)$. $\mathbf{d}$ The number of escapes accompanied with tongue-flick $(n=3)$ and without it $(n=21)$ a

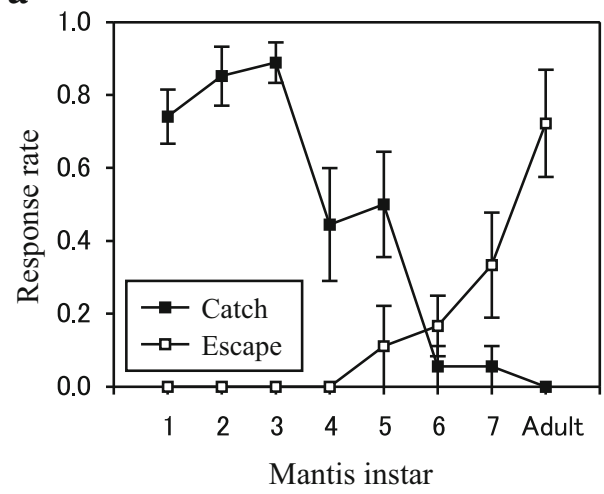

c

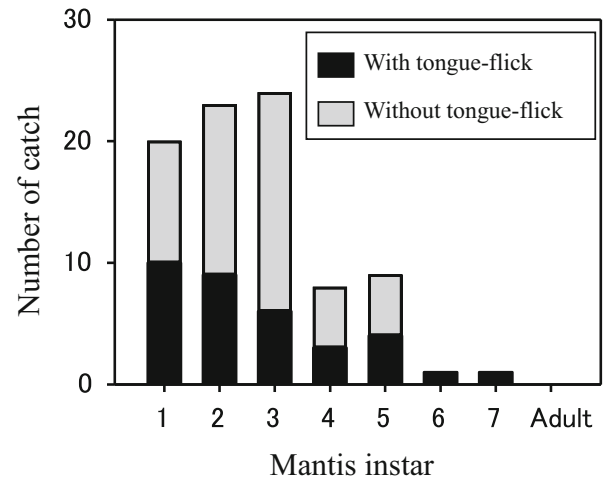

b

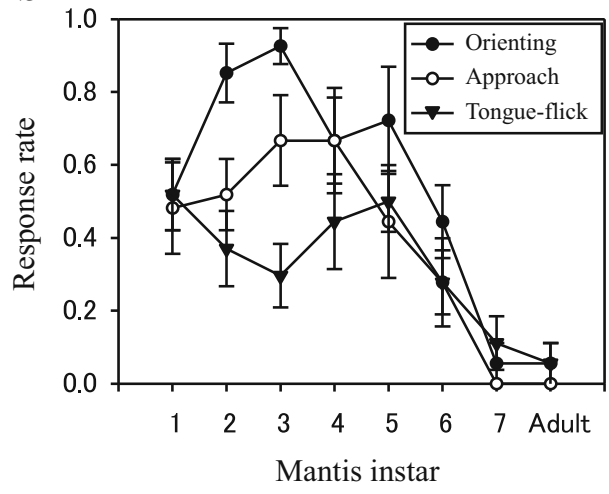

d

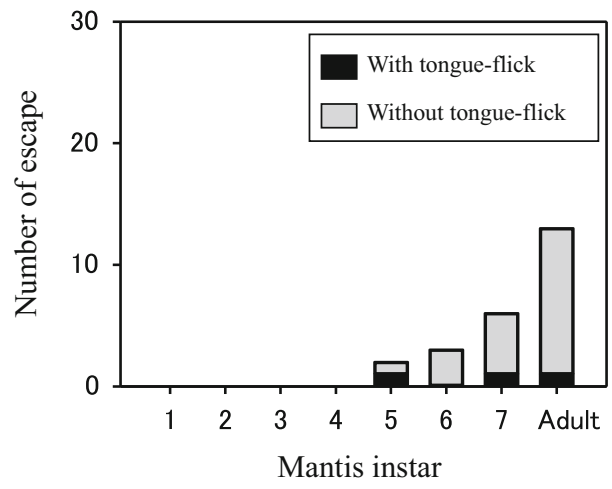



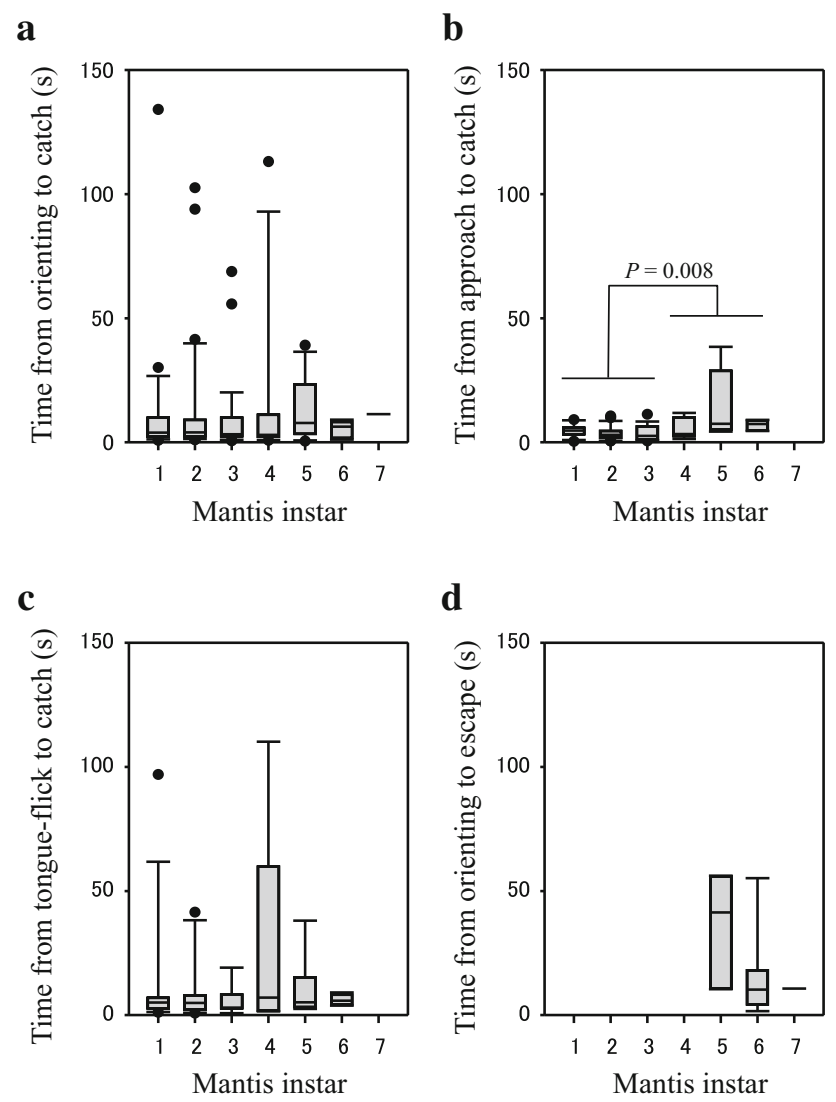

Fig. 3 Effects of the mantis instar on behavioural timing in the lizard. a Time from orienting to catch $(n=112)$. b Time from approach to catch $(n=75)$. c Time from tongue-flick to catch $(n=47)$. $\mathbf{d}$ Time from orienting to escape $(n=13)$. Data were from 305 responses of 12 lizards. $P$ value is indicated when there was significant effect. Boxes show the 25 th and 75 th percentiles and bisecting lines indicate the median value. Whiskers indicate the 5th and 95th percentiles and outliers are plotted

and tongue-flick to catch were 4.0 and $5.1 \mathrm{~s}$, respectively. When data of all mantis instars were pooled, time from orienting to catch was significantly longer for catch accompanied with tongue-flick than without it (Fig. 4a; MWT, $\left.n_{1}=42, n_{2}=31, U=357.5, P=0.001\right)$.

There was no significant correlation between the time from orienting to escape and the mantis instar (Fig. 3d; $\left.n=13, r_{\mathrm{s}} .=-0.365, P=0.206\right)$, and the median time was $10.6 \mathrm{~s}$. When data of all mantis instars were pooled, the time from orienting to escape was significantly longer than time to catch (Fig. 4b; MWT, $n_{1}=13, n_{2}=112$, $U=399.5, P=0.008)$.

\section{Effects of the mantis response on catch and tongue- flick responses in lizards}

Younger mantises tended to show primary defence such as immobility, cryptic and subcryptic responses, whereas
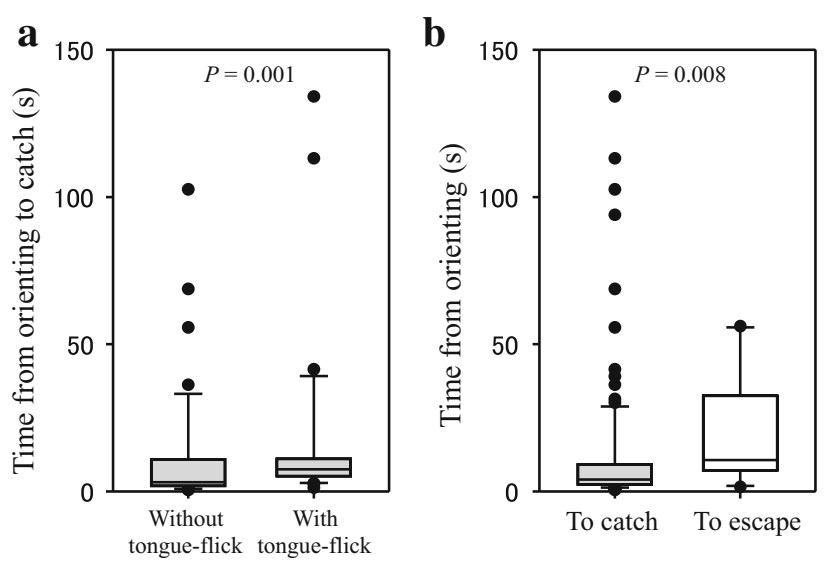

Fig. 4 Comparison of timing among behavioural responses in the lizard. a Time from orienting to catch accompanied with tongue-flick $(n=31)$ or without it $(n=42)$. b The time from orienting to catch $(n=112)$ or escape $(n=13)$

older mantises tended to show secondary defence such as deimatic and defensive strike responses (Fig. 5). The younger mantises from first to third instars sometimes showed no response before being caught by the lizard. Immobility response was observed mainly in younger mantises from first to third instars. Cryptic and subcryptic responses were observed mainly in mantises younger than fourth instar (S3). All instars and adult of mantises showed escape run. Deimatic and defensive strike responses were observed in mantises older than fourth instar (S4). Only seventh instar and adult mantises occasionally showed catch responses. The lizard caught all the younger mantises (from first to third instars) showing no response (Fig. 6). When the younger mantises showed some defensive responses, however, the lizard did not always catch them. Because sample size for each mantis instar was small, we further pooled data of younger mantises (from first to third instars) and all defensive responses. In these pooled data, defensive responses of the mantis significantly affected the catch responses of the lizard (Table 2; Fisher's exact test, $P<0.001$ ). However, primary defensive responses of the mantis did not significantly affect the tongue-flick responses of the lizard (Table 3; Fisher's exact test, $P=0.320$ ). The lizard did not always catch middle instar mantises (fourth and fifth instars) showing some defensive responses (Fig. 6). However, there was no significant effect of the mantis defence on the lizard catch responses in this case (Table 2; $P=0.300$ ). The lizard seldom caught older mantises (from sixth instar to adult) irrespective of the type of defensive responses (Fig. 6). It was difficult to test the effects of defensive responses in older mantises because there were few observations of no-response in them. 
Fig. 5 Behavioural responses of the mantises to lizards as a function of mantis instar. See text for the definition of mantis behaviours. Data were from 305 responses of 189 mantises

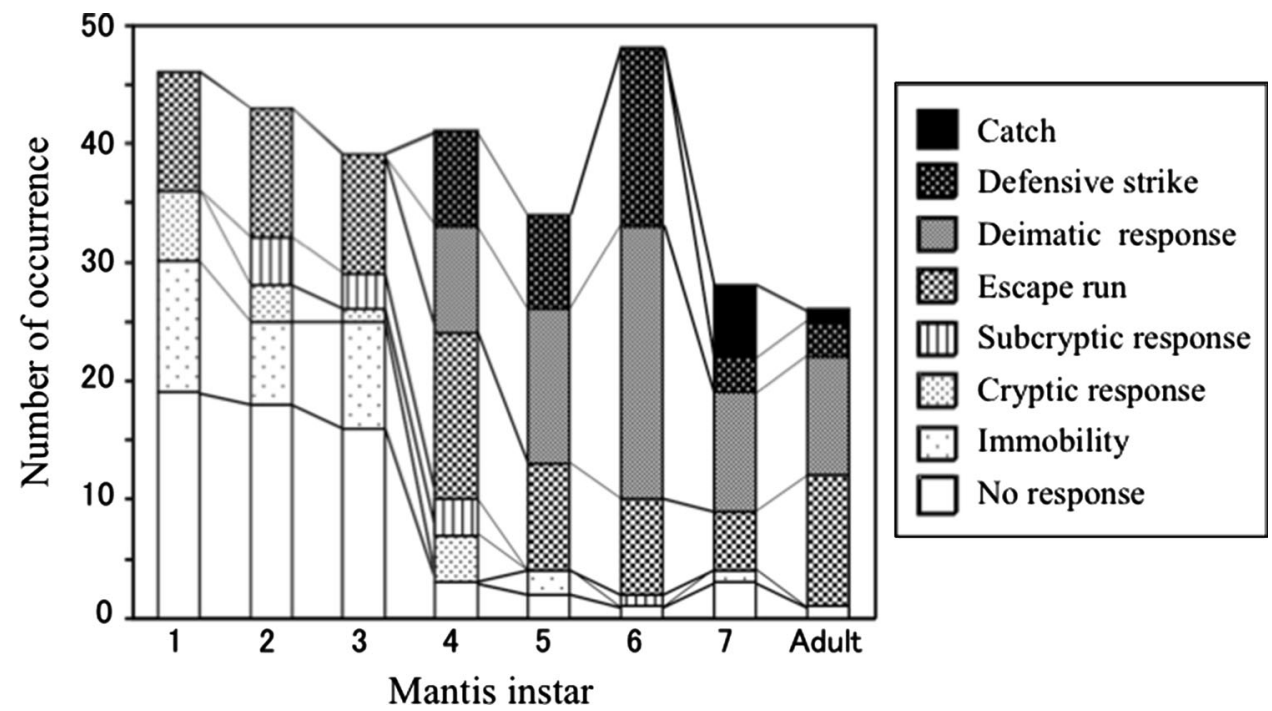

\section{Effects of deimatic response of the mantis on behavioural timing in lizards}

There was no significant difference in time from orienting to catch between trials with and without deimatic responses (Fig. 7; MWT, $n_{1}=21, n_{2}=8, U=66.0, P=0.393$ ).

\section{Discussion}

\section{Prey-predator relationship between the lizard and the mantis}

The interaction between Ta. tachydromoides and Te. aridifolia likely represents a type of intraguild predation, which is defined as the eating of competitor species that use similar resources (Polis and Holt 1992). Both the lizard and the mantis are found in grassland and are generalist predators, and their food consists of insects, spiders and small invertebrates (e.g. Jackson and Telford 1975; Barrows 1984; Reitze and Nentwig 1991). Hence, it is likely that the lizard and the mantis compete for similar food resources. Jackson and Telford (1975) have reported that mantis nymphs $1 \mathrm{~cm}$ or less in length were found in stomachs of wild Ta. tachydromoides. They have also pointed out that adult mantises are not only too large as prey but may occasionally prey upon young lizards. These studies and our results suggest intraguild predation between the lizard and the mantis. Because of ethical problems and the difficulty in collecting many lizards, we did not directly observe that the mantis ingested the lizard. However, the catch responses of the large mantises suggested that they recognize the lizards as potential prey. In addition, the escape run and tail waving responses of the lizards suggested that the lizards recognize large mantises as potential predators. It should be noted that the hunger level of the mantis was not systematically controlled in the present study. Hence, it is possible that some mantises were not hungry enough to attempt to catch relatively large prey, i.e. the lizard. The mantis might show catch responses more frequently if they were presented with juvenile lizards. The potential predation on juvenile vertebrates by invertebrate predators has been reported, for example, in wolf spiders (e.g. Rubbo et al. 2001, 2003) and ground beetles (e.g. Ovaska and Smith 1988; Gall et al. 2003).

\section{Prey and predator recognition in the lizard}

It has been suggested that sensory cues used by lizards for prey recognition are highly correlated with the foraging modes, ambush and active foraging (e.g. Huey and Pianka 1981; Cooper 1995, 1997). Ambush foragers, which remain stationary during waiting for prey to approach, rely on vision to detect prey (e.g. Cooper 1989; Ammanna et al. 2014), whereas active foragers, which move through the habitat searching for prey, use both visual and chemical cues to find prey (e.g. Cooper et al. 2000). Detecting chemical cues could be important for identifying visually detected potential prey or for locating hidden prey (Vitt and Cooper 1986; Cooper and Vitt 1989). Takydromus tachydromoides belongs to the family Lacertidae, some species of which are active foragers (e.g. Huey and Pianka 1981) and respond to prey chemicals (e.g. Cooper 1990a; Cooper et al. 2000; Desfilis et al. 2003). For example, Ta. sexlineatus bites cotton swabs carrying cricket odour more often than those with water and lettuce odours (Cooper et al. 2000). 
Fig. 6 Effects of mantis defence on the lizard catch behaviour. The number of occurrences in which the mantis was caught by the lizard or not was plotted as a function of mantis defensive responses. Data were divided into eight groups according to the mantis instar
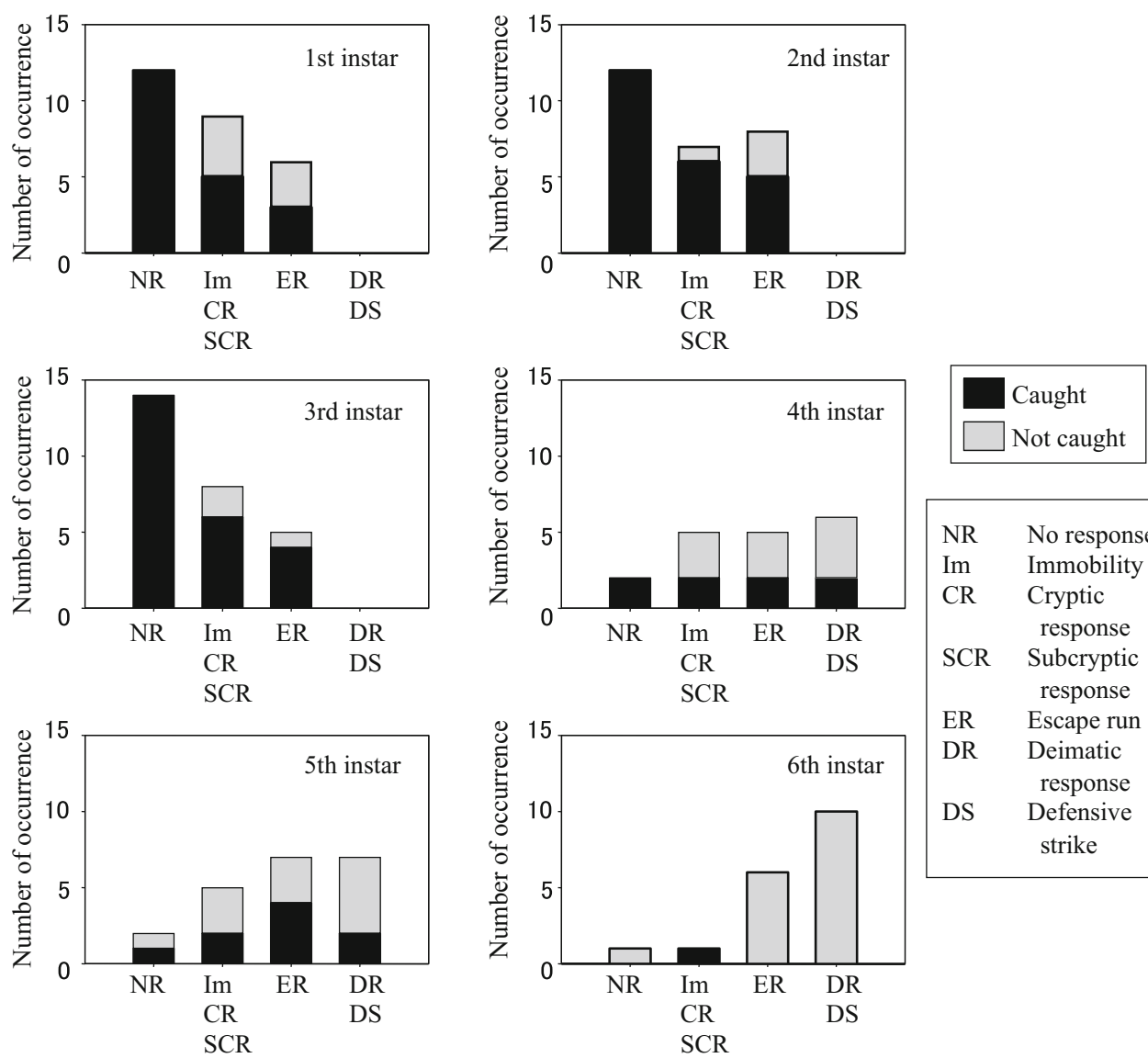

Not caught

NR No response Im Immobility CR Cryptic response SCR Subcryptic response ER Escape run DR Deimatic response DS Defensive strike

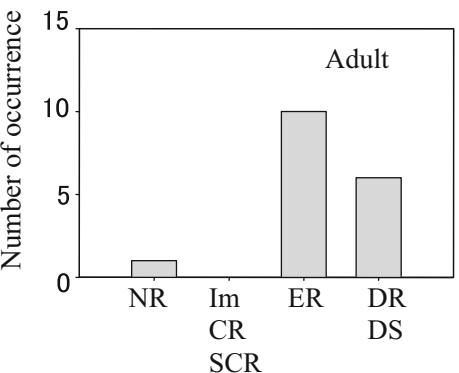

Table 2 Effects of the mantis defence on the lizard catch response

\begin{tabular}{lcllll}
\hline Mantis response & \multicolumn{2}{l}{ 1st-3rd instars } & & \multicolumn{2}{l}{ 4th-5th instars } \\
\cline { 2 - 3 } \cline { 5 - 6 } & No response & Defence & & No response & Defence \\
\hline Caught & 36 & 29 & 3 & 14 \\
Not caught & 0 & 14 & & 21 \\
\hline
\end{tabular}

The present results suggested that $T a$. tachydromoides mainly relies on visual cues (such as size and movements) for the decision to catch the mantis. Tongue-flick (chemical detection) did not always precede catch, suggesting that chemical cues are not always necessary for recognizing the mantis as prey. The primary role of vision has also been reported in other lizards that use both visual and chemical cues for prey recognition (e.g. Nicoletto 1985a, b). The
Table 3 Effects of the mantis defence on the lizard tongue-flick response

\begin{tabular}{lll}
\hline Lizard response & \multicolumn{2}{l}{ Mantis response (1st-3rd instars) } \\
\cline { 2 - 3 } & $\begin{array}{ll}\text { Immobility } \\
\text { Cryptic response } \\
\end{array}$ & Subcryptic response \\
\hline Tongue-flick & 7 & 25 \\
No tongue-flick & 17 & 32 \\
\hline
\end{tabular}

skink Scincella lateralis, for example, frequently attacks a live cockroach sealed in a transparent case, which prevents the skink from detecting chemical cues (Nicoletto 1985a).

The sensory cues used for prey recognition in $T a$. tachydromoides might depend on prey type, as reported in 


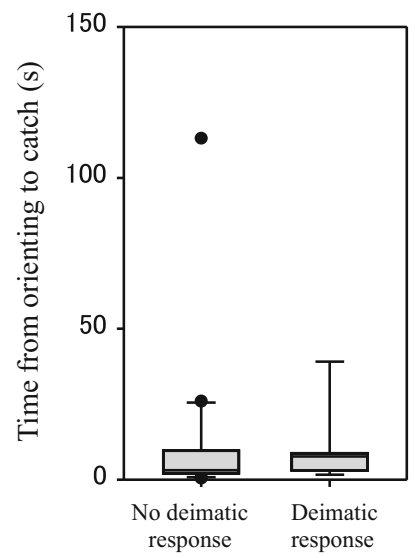

Fig. 7 Effect of deimatic responses of the mantis on time from orienting to catch in the lizard. Data were divided into two groups according to whether large mantises (from fourth to sixth instars) showed deimatic responses $(n=21)$ or not $(n=8)$. Boxes show the 25th and 75th percentiles and bisecting lines indicate the median value. Whiskers indicate the 5th and 95th percentiles and outliers are plotted

the skink Plestiodon latiscutatus (Hasegawa and Taniguchi 1993, 1994, 1996). This skink catches preferred prey without tongue-flick but rejects unpreferred (often chemically defended) prey at various stages after visual detection, tongue-flick or biting (Hasegawa and Taniguchi 1996). Hasegawa and Taniguchi (1996) have suggested that fast predatory attack immediately after visual detection is important for successful prey capture, especially when the prey is highly mobile. This might also be the case in $T a$. tachydromoides.

Because the lizard caught small mantises but escaped from large mantises, the size of the mantis seemed an important factor that strongly affectd the lizard response. It is less likely that the shape and colours of the mantis affected the lizard response because the shape and colours of mantises looked similar irrespective of instars. The effects of size on prey recognition have also been reported in several species of lizards (e.g. Burghardt 1964; Chen and Jiang 2006; Cooper and Stankowich 2010). The skink Plestiodon chinensis, for example, eats more prey of 11-20 $\mathrm{mm}$ in length than those of other lengths (Chen and Jiang 2006). Because the handling time (until completely swallowing the prey) increases exponentially as prey size increases over $25 \mathrm{~mm}$, it has been suggested that size preference in $P$. chinensis maximizes the rate of energy intake (Chen and Jiang 2006). The long handling time during swallowing large mantises was also observed in the present study. However, it is possible that not only the rate of energy intake but also the risk of predation or counter-attack by prey affect the size preference in $T a$. tachydromoides, as reported in blindsnakes (Webb and Shine 1993).
The present results also suggested that Ta. tachydromoides mainly relies on visual cues for recognising the mantis as predator. Chemosensory recognition of a predator has been reported in several lizard species (e.g. Mori and Hasegawa 1999; Webb et al. 2009; Martin et al. 2015). However, in Ta. tachydromoides, tongue-flick responses did not precede most escapes, suggesting that chemical cues are not always necessary for recognising the mantis as a predator. In addition, most lizards escaped from the mantises older than seventh instar without orienting, suggesting that the lizard does not necessarily inspect the potential predator with binocular vision before deciding to escape.

\section{Foraging and escape strategies in the lizard}

The time that the lizards spends before decision making to catch or escape might increase when the lizards attempt to obtain more information about the prey. For example, the lizards spent a longer time from approach to catch against larger mantises. This might reflect the attempt to obtain more information about large mantises in order to avoid their counter-attack. We sometimes observed that $T a$. tachydromoides bit the head of the large mantises. Attack to the head of prey has been reported in other species of lizards (e.g. Cooper 1981a, b). It is likely that the lizards bite the effective position of the large mantises (e.g. their head) to avoid their counter-attack. This task requires sufficient assessment of the mantis shape. Hence, the lizards might spend a longer time to decide where to bite against larger mantises.

The lizards spent a longer time from orienting to catch when catch was preceded by tongue-flick than catch without tongue-flick. This longer time might reflect the lizard's attempt to obtain more chemical information about the prey. It is less likely that the lizards use chemical cues when visual cues are insufficient because the occurrence of tongue-flick did not increase when the mantis ceased its movements in primary defensive responses (Table 3). When their motivation for catching is low, the lizards might assess prey with chemical cues.

The lizards spent a longer time from orienting to escape than to catch. This might reflect the conflict between catch and escape. The lizards might not need to escape quickly because their running speed seems higher than that of the mantis. Hence, when the prey was around capturable size (for example, fifth instar mantises), the lizards might elaborately attempt to obtain more information about the prey before deciding to escape. It is also possible that the lizards wait until an appropriate moment to escape, for example, when the mantis does not look at the lizards' head or body. Rapid movements might be risky because it can elicit a mantis attack (e.g. Prete et al. 1993). Further studies 
by controlling visual and chemical cues of the prey are required to test these possibilities.

\section{Defence strategy in the mantis}

In the present study, the mantis changed defensive responses depending on their developmental stage, as reported in previous studies (Liske et al. 1999; Watanabe and Yano 2010). It has been suggested that this behavioural change in defence is due to the relationship between speed of response and body size (Edmunds and Brunner 1999). Small mantises can run so quickly that a predator may fail to catch them, while the initial movement of large mantises is slower than that of small mantises because of their weight and mass. In addition, it is likely that immobility and cryptic tactics are more effective as the mantis is smaller. Hence, it might be relatively adaptive for large mantises to adopt secondary defences such as deimatic and defensive strike responses.

The present results also confirmed that the defence of small mantises is effective for avoiding predation by the lizards: the small mantises showing defensive responses were less frequently caught by the lizards than the mantises with no response. Mantis defensive responses also affect the responses of P. latiscutatus (Hasegawa and Taniguchi 1996): most mantises showing immobility or cryptic responses are not eaten, probably because the skink did not visually detect them. Primary defence might be effective especially to avoid predation by visually orienting lizards. However, the small mantises sometimes showed no response before being caught by the lizards, suggesting that they sometimes failed to detect the lizards.

We were not able to test the effects of secondary defence such as deimatic and defensive strike responses because there were few controls for comparison: only a few large mantises showed no response. Further studies are required to examine the effects of secondary defence, using manipulation experiments such as surgery treatments of blinding or inactivating the large mantises.

\section{Conclusion}

The present study is a first attempt to quantitatively analyse the behavioural interactions between Ta. tachydromoides and Te. aridifolia. Our results suggest intraguild predation between them. Because intraguild predation has effects combining predation and competition, its impact on population dynamics in food webs is more complex than either competition or predation alone (Polis and Holt 1992). In a similar sense, it is likely that intraguild predation makes foraging and escape strategies in Ta. tachydromoides and
Te. aridifolia more complicated. Further analysis of their behavioural strategies is needed under this perspective.

Acknowledgments We thank Akira Mori of Kyoto University for helpful advice and Teiich Tanimura of Kyushu University for providing fruit flies.

\section{Compliance with ethical standards}

Conflict of interest The authors declare that there is no conflict of interest.

\section{References}

Ammanna VHF, Saidapur SK, Shanbhag BA (2014) Prey detection in juveniles of an agamid lizard, Calotes versicolor (Daudin, 1802) (Reptilia: Squamata). Ital J Zool 81:155-159

Barrows EM (1984) Perch sites and food of adult Chinese mantids (Dictyoptera: Mantidae). Proc Entomol Soc Wash 86:898-901

Brooks GR Jr (1963) Food habits of the ground skink. Quart J Fla Acad Sci 26:361-367

Burghardt GM (1964) Effects of prey size and movement on the feeding behavior of the lizards Anolis carolinensis and Eumeces fasciatus. Copeia 1964:576-578

Burghardt GM (1973) Chemical release of prey attack: extension to naive newly hatched lizards, Eumeces fasciatus. Copeia 1973:178-181

Chen X, Jiang Y (2006) Diet of Chinese skink, Eumeces chinensis: is prey size important? Integr Zool 1:59-66

Cooper WE Jr (1981a) Visual guidance of predatory attack by a scincid lizard, Eumeces laticeps. Anim Behav 29:1127-1136

Cooper WE Jr (1981b) Head-first swallowing of large prey by a scincid lizard, Eumeces laticeps. J Herpetol 15:371-373

Cooper WE Jr (1989) Absence of prey odor discrimination by iguanid and agamid lizards in applicator tests. Copeia 1989:472-478

Cooper WE Jr (1990a) Prey odor detection by teiid and lacertid lizards and the relationship of prey odor detection to foraging mode in lizard families. Copeia 1990:237-242

Cooper WE Jr (1990b) Prey odor discrimination by anguid lizards. Herpetologica 46:183-190

Cooper WE Jr (1995) Foraging mode, prey chemical discrimination, and phylogeny in lizards. Anim Behav 50:973-985

Cooper WE Jr (1997) Correlated evolution of prey chemical discrimination with foraging, lingual morphology and vomeronasal chemoreceptor abundance in lizards. Behav Ecol Sociobiol 41:257-265

Cooper WE Jr, Stankowich T (2010) Prey or predator? Body size of an approaching animal affects decisions to attack or escape. Behav Ecol 21:1278-1284

Cooper WE Jr, Vitt LJ (1989) Prey odor discrimination by the broadheaded skink (Eumeces laticeps). J Exp Zool 249:11-16

Cooper WE Jr, Paulissen M, Habegger J (2000) Discrimination of prey, but not plant, chemicals by actively foraging, insectivorous lizards, the lacertid Takydromus sexlineatus and the teiid Cnemidophorus gularis. J Chem Ecol 26:1623-1634

Desfilis E, Font E, Guillen-Salazar F (2003) Stimulus control of predatory behavior by the Iberian wall lizard (Podarcis hispanica, Sauria, Lacertidae): effects of familiarity with prey. J Comp Psychol 117:309-316

Edmunds M, Brunner D (1999) Ethology of defenses against predators. In: Prete FR, Wells H, Wells PH, Hurd LE (eds) 
The praying mantids. Johns Hopkins University Press, Baltimore, pp 276-299

Gall S, Anthony C, Wicknick J (2003) Do behavioral interactions between salamanders and beetles indicate a guild relationship? Am Midl Nat 149:363-374

Hasegawa M, Taniguchi Y (1993) Visual prey discrimination of queen and worker ants by a generalist lizard. J Ethol 11:55-62

Hasegawa M, Taniguchi Y (1994) Visual avoidance of a conspicuously colored carabid beetle Dischissus mirandus by the lizard Eumeces okadae. J Ethol 12:9-14

Hasegawa M, Taniguchi Y (1996) Behavioral discrimination of prey with various defense mechanisms by the lizard Eumeces okadae. J Ethol 14:89-97

Huey RB, Pianka ER (1981) Ecological consequences of foraging mode. Ecology 62:991-999

Jackson DR, Telford SR Jr (1975) Food habits and predatory role of Japanese lacertid Takydromus tachydromoides. Copeia 1975:343-351

Johki Y, Hidaka T (1979) Function of the "warning coloration" in larvae of a diurnal moth, Pryeria sinica Moore (Lepidoptera, Zygaenidae). Appl Entomol Zool 14:164-172

Johki Y, Hidaka T (1982) Predatory behavior and learning in the lacertid lizard, Takydromus tachydromoides, toward unpalatable prey insects. Zool Mag 91:239-244

Kevan DK (1985) The mantis and the serpent. Entomol Month Mag 121:1-8

Liske E, Köchy K, Wolf H (1999) Ontogeny of defensive behaviors. In: Prete FR, Wells H, Wells PH, Hurd LE (eds) The praying mantids. Johns Hopkins University Press, Baltimore, pp 253-275

Maldonado H (1970) The deimatic reaction in the praying mantis Stagmatoptera biocellata. Z Vergl Physiol 68:60-71

Martin J, Ortega J, Lopez P (2015) Experience may allow increasing accuracy of the innate chemosensory recognition of snake predators by Iberian wall lizards. Behav Ecol Sociobiol 69: $1565-1572$

Mori A (1990) Tail vibration of the Japanese grass lizard Takydromus tachydromoides as a tactic against a snake predator. J Ethol 8:81-88

Mori A (1991) Spontaneous immobility of the Japanese lacertid lizard, Takydromus tachydromoides. Jpn J Herpetol 14:1-5

Mori A, Hasegawa M (1999) Geographic differences in behavioral responses of hatchling lizards (Eumeces okadae) to snakepredator chemicals. Jpn J Herpetol 18:45-56

Nicoletto PF (1985a) The relative roles of vision and olfaction in prey detection by the ground skink, Scincella lateralis. J Herpetol 19:411-415
Nicoletto PF (1985b) The roles of vision and the chemical senses in predatory behavior of the skink, Scincella lateralis. J Herpetol 19:487-491

Ovaska K, Smith MA (1988) Predatory behavior of 2 species of ground beetles (Coleoptera, Carabidae) towards juvenile salamanders (Plethodon vehiculum). Can J Zool 66:599-604

Polis GA, Holt RD (1992) Intraguild predation: the dynamics of complex trophic interactions. Trends Ecol Evol 7:151-154

Prete FR, Placek PJ, Wilson MA, Mahaffey RJ, Nemcek RR (1993) Stimulus speed and order of presentation effect the visually released predatory behaviours of the praying mantis Sphodromantis lineola (Burr.). Brain Behav Evol 42:281-294

Reitze M, Nentwig W (1991) Comparative investigations into the feeding ecology of six Mantodea species. Oecologia 86:568-574

Robinson MH (1969) Defenses against visually hunting predators. In: Dobzhansky T, Hecht MK, Steere WC (eds) Evolutionary biology. Meredith, New York, pp 225-259

Rubbo MJ, Townsend VR, Smyers SD, Jaeger RG (2001) The potential for invertebrate-vertebrate intraguild predation: the predatory relationship between wolf spiders (Gladicosa pulchra) and ground skinks (Scincella lateralis). Can J Zool 79:1465-1471

Rubbo MJ, Townsend VR, Smyers SD, Jaeger RG (2003) An experimental assessment of invertebrate/vertebrate predation: the interaction between wolf spiders (Gladicosa pulchra) and terrestrial salamanders (Ambystoma maculatum). J Zool 261:1-5

Telemeco RS, Baird TA, Shine R (2011) Tail waving in a lizard (Bassiana duperreyi) functions to deflect attacks rather than as a pursuit-deterrent signal. Anim Behav 82:369-375

Telford SR Jr (1997) The ecology of a symbiotic community: population biology of the Japanese lizard Takydromus tachydromoides and its parasitocenose. Krieger, Malabar

Vitt LJ, Cooper WE Jr (1986) Foraging and diet of a diurnal predator (Eumeces laticeps) feeding on hidden prey. J Herpetol 20:408-415

Watanabe H, Yano E (2010) Stage-specific defensive strategies of three mantid species, Tenodera aridifolia, Hierodura patellifera, and Statilia maculata, against a natural enemy, Takydromus tachydromoides. Ann Entomol Soc Am 103:293-299

Webb JK, Shine R (1993) Prey-size selection, gape limitation and predator vulnerability in Australian blindsnakes (Typhlopidae). Anim Behav 45:1117-1126

Webb JK, Du WG, Pike DA, Shine R (2009) Chemical cues from both dangerous and nondangerous snakes elicit antipredator behaviours from a nocturnal lizard. Anim Behav 77:1471-1478

Woodward G, Hildrew AG (2002) Body-size determinants of niche overlap and intraguild predation within a complex food web. J Anim Ecol 71:1063-1074 